\title{
PROBLEMAS QUE DIFICULTAM A IMPLEMENTAÇÃO DO PLANEJAMENTO DE SAÚDE *
}

\author{
Aldo da Fonseca Tinôco **
}

Tinóco, A. DA F. Problemas que dificultam a implementação do planejamento de saúde. Rev. Saúde públ., S. Paulo, 14:246-52, 1980.

RESUMO: São relacionados alguns problemas que dificultam a atividade de planejadores e administradores de sistemas de serviços de saúde quando se propóem a desenvolver aşōes planejadas no campo da saúde pública. Entre estes destacam-se aqueles que se referem à eleição de técnica, fixação de prioridades, organização e integraşão de serviços, informação estatistica e decisão politica.

UNITERMOS: Saúde pública, planejamento. Saủde pública, administração. Serviços de saúde.

A saúde, como um dos componentes do bem-estar e conseqüentemente do nivel de vida ${ }^{11,14}$, está a exigir a atenção crecente de politicos e administradores e a mobilização cada vez mais acentuada de recursos humanos e materiais, tornando-se mesmo nos dias que correm um dos setores mais complexos da sociedade.

Essa complexidade decorre de vários fatores, como os que são apresentados por Mascarenhas ${ }^{10}$, ao relacionar os aspectos evolutivos da medicina e da saúde pública:

a. Crescente desenvolvimento cientifico da medicina demonstrado pelos progressos observados na anestesia, na transfusão, na assepsia, na cirurgia, imunologia, bacteriologia e virulogia; progressos ainda observados no diagnóstico (roentgenfotografia pulmonar, radioisótopos, punção biópsia, citologia, endoscopia) e na terapêutica (antibióticos, sulfonamidas, vitaminas, antihistamínicos, hipotensores, vacinas, etc.) e ainda progressos derivados do surgimento de aparelhos suplementares de funçōes vitais, como ressuscitadores, rins e coração artificiais.

b. Crescente desenvolvimento das especializações médicas.

c. Crescente desenvolvimento do ensino e da prática profissional.

d. Crescente encarecimento das atividades médicas.

e. A formação de equipes para a execução de atividades médicas é prática que se observa com maior intensidade principalmente nos centros urbanos.

f. A saúde pública passou a dispor de novos métodos para a abordagem de pro-

* Parte da Tese de Livre-Docéncla apresentada à Faculdade de Saúde Pública da USP, em 1978, subordinada ao título "Sistemas de saúle e planejamento".

* Do Departamento de Prática de Saúde Pública da USP - Av. Dr. Arnaldo, 715 - 01255 São Paulo, SP - Brasil. 
TINoCO, A. da F. Problemas que dificultam a implementação do planejamento de saúde. Rev. Saúde públ., S. Paulo, 14:246-52, 1980.

blemas de saúde de massa não apenas no campo do diagnóstico como da terapêutica.

g. A saúde pública passou a contar, como indispensável, com o concurso de novos técnicos como o educador, o veterinário, o nutricionista, o assistente social, etc.

h. A saúde pública passou a se utilizar pouco a pouco da "técnica de planejamento único para a assistência integral preventivo-curativa".

Quanto aos aspectos sócio-econômicos, o mesmo autor 10 refere-se entre outros aos seguintes:

a. O "envelhecimento" da população com repercussões em problemas médico-sócio-econômicos.

b. A redução do número de indigentes e o aumento de pessoas que vivem de salários mas que não podem arcar com a despesa de tratamento.

A esse elenco de causas que se refletem na complexidade crescente do setor saúde, poderá somar-se o chamado efeito/demonstração. Em função deste fenômeno, os sistemas de serviços de saúde passam a utilizar equipamentos sofisticados muitas vezes desnecessários, o que leva ao encarecimento da assistência médica. Esse encarecimento é decorrente não apenas, dos elevados custos dos equipamentos, mas também dos gastos com pessoal qualificado indispensável ao seu funcionamento e pela obsolescência. Como é sabido, em face do desenvolvimento tecnológico observado atualmente, um equipamento poderá tornarse rapidamente obsoleto, tendendo assim a ser substituído não por depreciação mas por tornar-se superado ante o surgimento de outro modelo. Aliás, em relação ao assunto Machado 9 , em conferência proferida em Salvador, na Escola Baiana de Medicina, em maio de 1977, afirmou o seguinte: "Toda medicina deve ser antes de tudo social; o médico deve saber interpretar e usar os recursos de que dispõe como complemento e jamais como substitutos de sua própria atividade". Depois de declarar que "é cada vez maior o número de comunidades que se voltam para o atendimento de uma elite com seus complicados aparelhos", conclui Machado: "Podemos ter pacientes que entram num hospital para tratar de uma bronco-pneumonia e vêm morrer depois de passar por uma sucessão de aparelhagens e ser atado a todos os fios. Lembro por exemplo o caso de um hospital onde existia um porão sem janelas que abrigava 80 crianças, enquanto seu diretor sonhava com a instalação de uma unidade de tratamento intensivo".

Do exposto, e em relação ao nosso pais, facilmente se depreende que um problema básico salta à vista e é originado da necessidade de organização e direção dos sistemas de serviços de saúde, para adequá-los à nova realidade política, social e administrativa. Numa apreciação sobre os aspectos administrativos do sistema de saúde existente no país à época da publicação julho de 1975 - da Lei Federal no 6.229 T e que hoje ainda praticamente subsiste, declara Seixas 15: "Devido ao baixo nível de coordenação e à ausência de objetivos comuns explícitos, esse sistema de saúde tem sido muitas vezes caracterizado como um não-sistema e é importante ter-se em mente essa realidade ao organizar o Sistema Nacional de Saúde, desde que modificações em uma de suas partes implicarão em alteraçōes no todo". Até a presente data verifica-se a existência de uma série de dificuldades para implementação do Sistema Nacional de Saúde, desde os aspectos meramente institucionais até aqueles de ordem prática, como os derivados da escassez de recursos observados na maioria dos Estados e na quase totalidade dos municipios. Esse problema referente à organização e direção dos sistemas de serviços de saúde, é comum a um grande número de paises, particularmente aqueles catalogados como pertencentes ao terceiro mundo, em relação aos quais não sabemos se são sub-desenvolvidos porque são mal administra- 
TINoCo, A. da F. Problemas que dificultam a implementação do planejamento de saúde. Rev. Saude pübl., S. Paulo, 14:246-52, 1980.

dos ou se mal administrados porque são sub-desenvolvidos *.

Mas, a ser verdadeiro esse ciclo vicioso, é de interesse das comunidades nacionais romper as amarras do sub-desenvolvimento e o planejamento como um processo racionalizador de decisões voltadas para a mudança de situações consideradas não-satisfatótias, tem um grande papel a desempenhar. Em decorrência desse fato, as organizações modernas passam a contar com unidades especializadas em determinadas funções - inclusive a função planejadora destinadas a contribuir para que os sistemas alcancem de forma mais efetiva os seus objetivos. Por outro lado, se é acentuado o crescimento das organizações, também é grande 0 volume de atividades a executar o que torna imprescindivel a delegação de autoridade e de atribuições nos diversos niveis da estrutura organizacional. O setor saúde, como é natural, não poderia fugir a essa tendência histórica.

Não obstante a constatação dessa realidade atual, ainda se observa de forma generalizada o não funcionamento dos sistemas de sèrviços de saúde com entrosamento completo entre as suas unidades estruturais. Nem mesmo existe a compreensão perfeita das atribuições do planejador e do administrador. Sobre o assunto, a Organização Panamericana de Saúde, em documento que elaborou sobre a Planificação de Saúde na América Latina ${ }^{12}$, assim se manifesta: "A função essencial da planificação é assessorar o Poder Executivo e para cumprir com essa função, o planificador se baseia na racionalização que emana da natureza e da metodologia da programação. Não obstante, o administrador também tem a sua própria forma de racionalizar, sua maneira de organizar e atuar. Muitas vezes se vê obrigado a adotar certos tipos de soluçōes que correspondem aos procedimentos tradicionais. A racionalização do administrador provavelmente não coincide com a do plani- ficador por que este seguramente há de sugerir mudanças tanto nos objetivos da politica como nas medidas administrativas, e, considerará a eficiência como função dessas mudanças. Portanto, não é surpreendente que a miúde surjam dificuldades entre os planificadores e administradores".

Reconhecido esse fato do não entrosamento entre algumas unidades de uma mesma organização, outro elemento a dificultar a consecução dos objetivos contidos nos planos é a problemática administrativa da execução. Para o exercicio da função aplicativa, necessário se faz a combinação de forma adequada dos recursos humanos e materiais, o que não se observa comumente.

Se as dificuldades são percebidas a nível de definição de atribuições, distribuição e utilização de recursos no "âmbito" de uma organização de saúde, elas se tornam mais evidentes quando consideradas no aspecto mais amplo do setor. Em relação ao caso brasileiro, o setor está dividido em público e privado e quanto ao primeiro, a sua distribuição pelos níveis político-administrativos (Federal, Estadual e Municipal) dificulta, quando não impede, o planejamento único e a integração de suas atividades. Mecanismos de ordem institucional devem ser acionados de forma a não ferir os principios constitucionais que regem a organização federativa brasileira, mas que tornem efetivos os objetivos maiores do Sistema Nacional de Saúde, que são aqueles voltados para a elevação do nivel de saúde do povo brasileiro. Esse aspecto institucional nos parece de grande importância pelo caráter intervencionista do planlejamento, que se refletirá inevitavelmente na estrutura da organização político-administrativa nacional.

Se à situação observada no setor público, for acrescentada a atuação do setor privado, fácil é deduzir-se dos obtáculos de ordem administrativa para conduzir de

\footnotetext{
* Drucker 5 refere-se a um dito popular na América Latina que estabelece o seguinte: "Os paises em desenvolvimento não são subdesenyolvidos mas sim sub-administrados".
} 
TINoco, A. da F. Problemas que dificultam a implementação do planejamento de saúde.

Rev. Saúde públ., S. Paulo, 14:246-52, 1980.

forma integrada órgãos tão díspares e muitas vezes de interesses não coincidentes, apesar de responsáveis pela prestação de serviços de saúde à população.

Quanto ao problema da não integração e descoordenação observados entre os vários órgãos prestadores de serviços de saúde, em nosso país, tanto do setor públi$\mathrm{co}$, como do setor privado, uma possibilidade de solução passa a existir com a promulgação da Lei Federal no 6.229 de 17 de julho de $1975^{7}$ que institucionalizou 0 Sistema Nacional de Saúde. A aplicação prática desta Lei é um desafio aos administradores de saúde do país.

Além dos problemas referentes às dificuldades de integraçao dos diversos órgaos voltados para a prestaçao de serviços de saúde e para a escassez de pessoal - não apenas aquele capacitado em planejamento do setor, mas também o pessoal responsável pela execução dos planos - outros problemas existem, e entre eles podem ser citados aqueles relacionados à informação estatística. Quanto a esta, nos países de baixo nivel de desenvolvimento, é normalmente escassa ou praticamente inexistente e, quando presente, é de tal natureza inadequada, que dificilmente poderá apresentar alguma utilidade prática. $\mathrm{O}$ diagnóstico da situação de saúde em áreas de programação revelará o estado da informação estatística. Quando esta inexistir ou se apresentar inadequada ao processo de planejamento, o administrador de saúde deverá desenvolver ações no sentido de suprir a falha, pois a informação estatística é pré-condição para o exercício de ações programadas de saúde.

Pode ocorrer que em algumas áreas mesmo desenvolvidas, a informação estatística inexista ou se apresente imprecisa, dificultando ou impedindo o trabalho do analista, conforme referem Barbosa ${ }^{2}$ e Leser 8 em estudos relativos ao município de São Paulo.

Swaroop ${ }^{16}$, por sua vez, afirma que as estatísticas de saúde são usadas entre outras coisas para: "a. Descrever o nível de saúde da comunidade.

b. Diagnosticar doenças de comunidade.

c. Descobrir soluçōes para os problemas de saúde e achar a chave para a ação administrativa.

d. Determinar prioridades para programas de saúde.

e. Dirigir ou manter controle durante a execução de programas de saúde.

f. Desenvolver procedimentos, definições, classificações e técnicas tais como sistemas de registros, esquemas para estabelecer amostras, etc.

g. Promover legislação sanitária.

h. Criar padrões administrativos de atividades de saúde".

Para o administrador sanitár.o poder executar o seu travalino $\mathrm{em}$ Dases racionals, é imprescinaivel o connecimento ua situaçao de saúde da comunıaade soo sua jurısdıçao. Esse conhecimento será possivel meurante a utılızaçáo da intormaçao estatístıca. Kamosis tratanco do assunto declara: "Em váras etapas do trabalho de saúde pública esse conhecimento é necessárı, mas em duas ocasiōes particulares assume ele importância fundamental: precedendo instalações dos serviços, a fim de possibilitar um planejamento de atividades ajustado à natureza e amplitude dos problemas existentes e depois de algum tempo de desenvolv:mento do programa de trabalho, para permitir avaliar os resultados obtidos, corrigir deficiências de execução, ampliar ou reduzir as atividades em determinados campos e eventualmente rever o sistema de prioridades para fazer face a novos problemas que tenham surgido".

No Brasil, os administradores de saúde pública ainda se ressentem da precariedade da informação estatística existente e registrada, que não atende ainda às necessidades do planejamento. Cumpre ressaltar, porém, que em algumas áreas do sistema se observa um certo esforço no sentido de 
TINOCO, A. da F. Problemas que dificultam a implementação do planejamento de saúde. Rev. Saúde puibl., S. Paulo, 14:246-52, 1980.

sanar essa falha. Cumpre àqueles que estão envolvidos com os problemas administrativos do campo da saúde, definir que informações são necessárias ao exercício pleno do processo de planejamento, considerando não apenas as que são pertinentes ao desempenho interno do sistema, mas aquelas originárias da própria comunidade e que se refletem no equilibrio e sobrevivência do sistema.

Planos podem ser elaborados e podem estar voltados para realidades mutáveis; no entanto, se o sistema responsável pela sua aplicação não dispuser de pessoal capacitado para a sua execução, os planos, por exequiiveis que sejam, jamais terão alcançado os seus objetivos. Por outro lado, sem dados adequados será impossivel para o sistema de saúde a elaboração de planos e o exercício pleno do processo de decisão. Para o exercício do processo decisório, o conhecimento e a informação estatística são imprescindiveis, Podemos adiantar mesmo que a credibilidade do administrador será assegurada ou não pelas decisões que tomar. Pelos efeitos que causa, a decisão se refletirá não apenas na consecução dos objetivos, mas no equilibrio do próprio sistema, no caso, o sistema de serviços de saúde. Em relação ao pessoal especializado em planejamento no setor saúde, a lacuna até então existente, vai pouco a pouco sendo corrigida em face dos cursos que vêm sendo desenvolvidos atualmente por algumas instituições.

Não são, porém, apenas os citados os grandes problemas a serem enfrentados pelos administradores, quando se propõem a desenvolver o processo de planejamento de saúde. Implantado o processo de planejamento, os administradores se interrogam em relação aos diversos caminhos que poderão seguir para modificar a situação de saúde da área de sua responsabilidade. Para o ataque a um problema de saúde, o administrador verifica que dispõe no seu arsenal técnico de "métodos preventivos" e "métodos curativos". Qual o que deve ser em- pregado ou a combinação de ambos os métodos é uma decisão que deve resultar de uma atitude especulativa e racionalizadora. É assim, uma decisão de eleição de técnica, como declara Ahumada e col. ${ }^{1}$. Numa organização estruturada em um sistema de complexidade crescente, esforços devem ser desenvolvidos no sentido de manter a população sem necessitar penetrar no interior do sistema, isto é, no estado são, como declara Chaves ${ }^{3}$. Neste caso, os métodos preventivos do primeiro e segundo niveis de Leavell e Clark $^{6}$ seriam aplicados. Na impossibilidade da sua aplicação, o procedimento "curativo" far-se-á necessário. Somente o diagnóstico da situação de saúde da área em que será desenvolvida a programação, indicará que técnica será "eleita" para o ataque ao problema ou problemas de saúde.

Como é sabido, as necessidades derivadas da perda da saúde são maiores do que os recursos existentes para satisfazê-las. Mesmo os países mais ricos não disporão de recursos suficientes para atacar simultaneamente todos os problemas de saúde. Nos paises pobres a situação, naturalmente, se apresenta mais grave. Do fato se origina um outro problema que é o da fixação de prioridades que deverá considerar que grupos da população devem ser beneficiaddos mais que outros e que danos devem ser combatidos com maior ou menor intensidade.

Para o conhecimento e compreensão da realidade complexa que será a situação de saúde da área programática, o administrador lançará mão do método científico mediante o emprego de instrumentos metodológicos adequados ao processo de planejamento das ações de saúde. Até o presente momento, não existe uma técnica metodológica que atenda a solução de conjunto para as situações de saúde, considerando as realidades locais ou regionais, bem como os aspectos administrativos que os sistemas de serviços de saúde muitas vezes apresentam. No entanto, as técnicas presente- 
TINoco, A. da F. Problemas que dificultam a implementação do planejamento de saúde. Rev. Saúde pribl., S. Paulo, 14:246-52, 1980.

mente existentes permitem o diagnóstico e a programação das ações de saúde, cabendo ao administrador selecionar aquela ou aquelas mais adequadas a cada situação particular.

Cumpre ressaltar que o setor saúde, de há muito, vem planejando as ações de saúde pública. É o planejamento tradicional, limitado a determinadas atividades ou instituições, sem apegar-se, porém, a "uma metodologia definida, objetiva e sistematizada" como afirma Tejada de Rivero ${ }^{17}$. As ações de saúde, até então, vinham sendo programadas "considerando-se o campo da saúde como independente ou isolado do contexto econômico e social, do qual é parte inseparável"17.

Em relação à saúde, o planejamento moderno se caracteriza, segundo Kamos ${ }^{14}$, pela vinculaçāo do planejamento de saúde à problemática do desenvolvimento, e pela preocupação em trazer para o campo da saúde a problemática da economia.

Para Tejada de Rivero ${ }^{17}$ a novidade no planejamento de saúde pode ser resumida nos seguintes pontos:

"a. Setorial, porque procura abranger todas as entidades produtoras de serviços e bens de saúde;

b. é integrada porque no setor interdependente com os outros é parte integrante do planejamento geral ou global de desenvolvimento econômico e social. As metas dos planos de saúde devem ser compatíveis com as metas do desenvolvimento. Os insumos que o setor requer devem sofrer apreciação em relação ao interesse para a produção dos demais setores econômicos e sociais, assim como a sua participação na politica geral de produção, de substituição de importações, de estímulos de mercados internos, etc.;

c. exige uma objetivação e quantificação nas mensurações das var áveis dependentes e controláveis do setor saúde, para a qual faz-se mister utilizar não só as ciências biológicas como também as sociais e matemáticas;

d. reconhece a ação determinante e causal de outros setores sócio-econômicos na problemática da saúde, procurando portanto circunscrever as açōes de saúde pública dentro de limites que compreendam, somerite, suas variáveis dependentes e controláveis;

e. enfatiza a necessidade de racionalização do uso dos recursos disponíveis pelo setor saúde, enfoque dentro do qual a administração e os serviços adm nistrativos têm, precisamente, um papel de preponderai.te importância".

Ao lado do que foi exposto, uma referêncaa especial deve ser icita à varıável politica que está no cerne de towos os pruolumas. Sem a volitaue manifesta de implantar e ciesenvolver o piocesio de planejamento por parte caqueles que det-m o poder de decisao, tor a-se impossival qualquer inciativa nesse senticio. INo Brasil, a partir do Decreto-Lei no 200 , de 25 de fevereiro de 1967*, do Governo Federal, o planejament, foi institucionalizado a nivel federal, estadual e mesmo em alguns municipios, órgãos com a responsabilidade especifica de planejar passaram a fazer parte da estrutura governamental, fato que estabelece condições politicas e administrativas favoráveis à programação em prat camente todos os setores.

Como se depreende, são múltiplos os problemas ro caminho dos adminustradores de sistemas de serviços de saúde, quancio se propõem a desenvolver ações planejadas de saúde. Desde aqueles localizacios no interior do setor, coms aqueles relacionados com outros setores exigem de administradores e planejadores, além do cunhecimento e compreensão da realidade, esforços no sentido de adequar os sistemas que dirigem ao processo de planejamento, bem como a criação de mecanismos de articulação inter-setorial para incluir a saúde as lado dos outros fatores essenciais ao desenvolvimerto da sociedade humana. 
TINOCO, A. da F. Problemas que dificultam a implementação do planejamento de saúde. Rev. Saude puibl., S. Paulo, 14:246-52, 1980.

RSPUB9/506

TINôco, A. DA F. [Health planning and the problems that make its implementation difficult]. Rev. Saúde públ., S. Paulo, 14:246-52, 1980.

ABSTRACT: Some problems that handicap the activity of health administrators and planners when they try to develop planned activities in public health are listed. Among such problems those regarding choice of techniques, establishment of priorities, organization and integration of services, statistical information, and policy decisions stand out.

UNITERMS: Health and welfare planning. Public health administration. Health services.

\section{REFERENCIAS BIBLIOGRAFICAS}

1. AHUMADA, J, et al. Problemas conceptuales e metodologicos de la programacion de la salud. Washington, DC, Organización Panamericana de la Salud, 1965. (OPAS - Publ. cient., 111).

2. Barbosa, V. O problema dos dados de estatística vital, sobretudo os dos óbitos e nascimentos vivos, no Município de São Paulo. Rev. Saúde públ., S. Paulo, 1:177-87, 1967.

3. CHAVES, M. M. Saude e sistemas. Rio de Janeiro, Fundação Getúlio Vargas, 1974.

4. DECRETO-LEI no 200: Dispōe sobre a organização administrativa federal, estabelece diretrizes para a reforma administrativa e dá outras providências. Diário Oficial da União, 28 mar. 1967.

5. DRUCKER, P. Administração, tarefas, responsabilidades, práticas. São Paulo, Ed. Pioneira, 1975. v. 1.

6. LEAVELL, H. R. \& CLARK, E. G. Medicina preventiva. Rio de Janeiro, Ed. McGraw-Hill do Brasil, 1976.

7. LEI n० 6.229 de 17 de julho de 1975: dispõe sobre a organização do Sistema Nacional de Saúde. Diário Oficial, Seção $I$, Parte I, Brasilia, 18 jul. 1975. p. 8921-2.

8. LESER, W. S. A mortalidade infantil no periodo de 1950-1970: influência dos fatores sócio-econômicos e ambientais no nivel de saúde. Probl. bras. 12(134): 16-29, 1974.

9. MACHADO, P. A. Ministro faz alerta sobre função social da medicina. A Folha de São Paulo, São Paulo, 1o jun. 1977. p. 7 .
10. MASCARENHAS, R. dos S. Introducão a administração sanitária. São Paulo, Faculdade de Saúde Pública - USP. Disciplina de Administração Sanitária, 1972. [Mimeografado]

11. MILANESI, L. \& LAURENTI, R. Estatistica vital. São Paulo, Faculdade de Higiene e Saúde Pública USP, 1968. [Mimeografado]

12. ORGANIZACION PANAMERICANA DE LA SALUD, Planifioacion de la salud en la América Latina. Washington. DC, 1973.

13. RAMOS, R. Indicadores do nivel de saúde: sua aplicaçāo no muricipio de São Paulo (1894-1959). São Paulo, 1962. [Tese de Doutoramento - Faculdade de Saúde Pública da USP]

14. RAMOS, R. Temas de planejamento de saúde. São Paulo, Facullade de Saúde Pública da USP, 1974. [Curso de Especialização em Planejamento do Setor Saúde. Trabalho docente, 49]

15. SEIXAS, J. C. Sistema Nacional de Saúde. In: Conferencia Nacional de Saúde, 5a., Brasília, 1975. Anais. Brasilia, Ministério da Saúde, 1975. p. 31-41.

16. SWAROOP, S. \& UEMURA, $\mathbf{K}$. Introduction to health statistics. Edinburg, E. \& S. Livingtone, 1960.

17. TEJADA DE RIVERO, D, et al. Os serviços administrativos nos planos nacionais de saúde. São Paulo, Faculdade de Saúde Pública USP, 1975. [Trabalho docente, 3]

Recebido para publicação em 26/11/1979 Aprovado para publicação em 21/02/1980 